See discussions, stats, and author profiles for this publication at: https://www.researchgate.net/publication/282356684

\title{
Evaluation of relationship between balance parameters and bone mineral density
}

Conference Paper · September 2015

DOI: 10.1109/ICBME.2015.7404167

CITATION

1

6 authors, including:

A Fatemeh Radaei

University of California, Davis

7 PUBLICATIONS 18 CITATIONS

SEE PROFILE

Shahriar Gharibzadeh

Shahid Beheshti University

37 PUBLICATIONS 145 CITATIONS

SEE PROFILE
READS

141

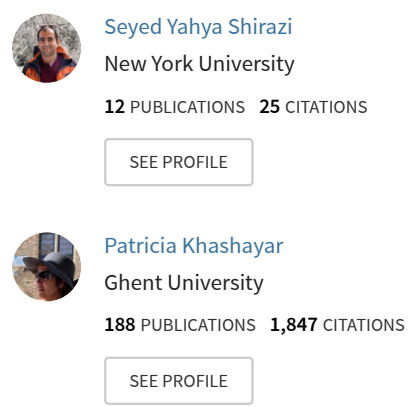

Some of the authors of this publication are also working on these related projects:

Intranasal premedication effect of Dexmedetomidine versus midazolam on 2-6 years old uncooperative children behavior in dental clinic View project

Osteokit View project 


\title{
Evaluation of relationship between balance parameters and bone mineral density
}

\author{
Fatemeh Radaei ${ }^{1}$, S. Yahya Shirazi ${ }^{1}$, Shahriar Gharibzadeh ${ }^{1}$, Patricia Khashayar ${ }^{2,3}$, Majid Ramezani ${ }^{2,4}$, Nasser \\ Fatouraee $^{1}$ \\ I. BIOMEDICAL ENGINEERING DEPARTMENT, AMIRKABIR UNIVERSITY OF TECHNOLOGY, TEHRAN, IRAN \\ II. Osteoporosis Research Center, Endocrinology and Metabolism Clinical Sciences Institute, Tehran University
OF Medical Sciences, TeHRan, IRAN
}

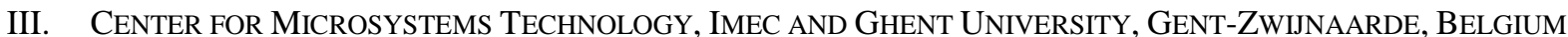

\section{ENDOCRINOLOGY AND METABOLISM RESEARCH CENTER, ENDOCRINOLOGY AND METABOLISM CLINICAL SCIENCES INSTITUTE, TEHRAN UNIVERSITY OF MEDICAL SCIENCES, TEHRAN, IRAN}

Corresponding e-mail: Nasser@aut.ac.ir

\begin{abstract}
In the present study, a group of people aged 20-85 who visited the bone mineral densitometry center of the Shariati Hospital, were analyzed. Participants were asked to stand up barefoot on Wii balance board and in front of a Kinect sensor. We calculated the center of pressure (COP) and center of mass (COM) using the data from Wii balance board and Kinect, respectively. By evaluating balance parameters, we show that there is a reverse relationship between center of mass acceleration and femur's bone mineral density. Further research in the subject may facilitate the design of equipment that can reduce the rate of falling in patients.
\end{abstract}

Keywords- falling; center of pressure; center of mass; acceleration of cneter of mass; Femur bone mineral density; Kinect, Wii balance board

\section{INTRODUCTION}

It is estimated that more than 200 million people around the world suffer from osteoporosis. The major complication of osteoporotic patients is the fragility fracture, which may decrease their quality of life and morbidity. Due to considerable health care related costs and the decrease in patients' quality of life, the study of fragility fracture has attracted a lot of attention. Indeed, several fracture predictors are studied in the literature. Baseline fracture is a useful predictor of further fractures for patients who experience a second fracture within the first year. [1] Another fracture predictor is Bone Mineral Density (BMD) which overlooks the possible fractures in osteopenia patients. Moreover, the WHO introduced the Fracture Risk Assessment Tool (FRAX) in 2008 to predict osteoporotic fractures through next 10 years in patients with osteopenia. FRAX is mainly based on the patients' age, fracture history, family history of hip fracture, cigarette smoking, long-term glucocortoid therapy, low body mass index (BMI), and excessive alcohol intake, with or without information of BMD. ${ }^{[2]}$ Indeed, since the disease is highly multifactorial, measuring just a single risk factor (like BMD) would not provide us with a comprehensive assessment of the fracture risks. ${ }^{[3]}$

Applying the WHO risk prediction algorithm to estimate hip fracture possibility through next 10 years, has facilitated efficient osteoporotic treatments. The US economic analysis also indicates that this application is cost-effective in osteoporotic patients. In addition, physicians report an absolute fracture risk, which is preferred to BMD. ${ }^{[4,5,6,7]}$

Osteoporotic fractures are mainly caused by falling and balance disorders. Thus, balance disorders are prevalent among osteoporotic patients. Balance is like a complex that receives various information from different organs to inform the body of where the body is. The data comes from vision, auditory, and joints. ${ }^{[8,9]}$

Osteoporosis is defined by the loss of bone mass, which may be due to various risk factors. ${ }^{[10]}$ It has been shown that the rate of bone turnover is higher in spongy bones (such as vertebral column) than compact bones. ${ }^{[11]}$ As a result, bone loss in vertebral column could lead to spinal curvature deformity. It is shown that there is a relationship between postural deformity and postural sway and instability. Also, postural instability has been considered a risk factor for falls and, as a result, osteoporotic fractures. ${ }^{[12]}$

Balance can be thought as the ability of body to control and keep the center of pressure (COP) on the base of support (BOS). ${ }^{[13]}$ There are several contributing factors, which affects one's level of stability: 1) size of the BOS: greater the BOS, the more stability one has; 2 ) height of the center of mass: increase in the 
height would decrease the level of stability (COM); 3) location of the COM on the BOS: if COM goes out of BOS, the moment of our body weight may cause a falling; 4) body mass: the more body mass we have, the more stability level we get; and 5) friction with BOS: it helps to have higher stability level. ${ }^{[14]}$

In some studies, it has been shown that the height of the COM decreases in osteoporotic patients, but its effect on patient's instability is not significant. Besides, a great loss of body mass has been reported in osteoporotic patients, which has a negative effect on their stability. ${ }^{[15]}$ In addition, there is a possibility that BMD loss affects the COM by causing a change in the body posture, and thus perturbs one's stability. ${ }^{[16]}$

In several previous studies, the difference between "COPCOM" is defined as the "balance error" which correlates with the horizontal acceleration of the body and can be used to determine the postural stability in falling. ${ }^{[17,18,19]}$

From another perspective, there are psychometric properties that can be attributed to one's falling, such as fear of falling. Thus to target appropriate interventions, assessment of fear of falling is crucial in promoting independence, function, wellness, and safety of older adults. The Falls Efficacy ScaleInternational (FES-I) is a short, easy to administer tool that measures the level of concern about falling during social and physical activities inside and outside the home whether or not the person actually does the activity. The level of concern is measured on a four point scale $(1=$ not at all concerned to $4=$ very concerned) ${ }^{[20,21]}$ Furthermore, there is another method, ABC scale, which provides us with additional psychometric support for FES. It is also more suitable to detect loss of balancing confidence in more highly functioning seniors. Greater situation-specificity of items may also assist clinicians in targeting appropriate interventions. ${ }^{[22]}$

\section{MATERIALS AND METHOD}

In this cross sectional study, people aged 20-85 who visited the bone mineral densitometry center of the Shariati Hospistal were included. For every person the descriptive information, accident and fracture history, and underlying diseases were collected by three different questionnaires. Next, dynamic information from Wii Balance board and Kinematic information from Kinect were assessed.

\section{A. Subjects}

People aged 20-85 who had undergone bone mineral densitometry in the BMD center of the Shariati Hospital in Spring 2015 were considered for the study.

Considering the low prevalence of Osteoporosis in men, men were excluded from the study. In addition, people with the following conditions were excluded, leaving five women, eligible for the study:

Any disease which impairs one's independency that does not let the person to participate in our tests: using walker through daily activities, having prosthesis in the body, any neurologic disorder, diabetic people, rheumatologic people with muscular weakness, osteoarthritis, people with poor sight vision, people with poor auditory system, any structural impairment and deformity, and history of using glucocorticoids drugs.

The study was approved by the ethics committee of Endocrinology and Metabolism Research Institute affiliated to Tehran University of Medical Sciences.

\section{B. Measurements}

We collected the data using DXA machine (Lunar, 7164, GE, Madison, WI), Kinect 1 (Microsoft Corp., Redmond, WA, US), and Wii Balance Board (Nintendo Co. Ltd., Kyoto, Japan).

We assessed the balance parameters by Kinect 1 and Wii balance board. Participants were asked to stand up bare foot on Wii balance board, which were in front of Kinect. The test duration was 60s. Kinect data acquisition frequency was $30 \mathrm{~Hz}$ and Wii balance board frequency was $40 \mathrm{~Hz}$. Both data were filtered using Butterworth $6^{\text {th }}$ order low pass filter with $8 \mathrm{~Hz}$ cutoff frequency.

\section{Statistical analysis}

For statistical analysis, using PASS 14 and NCSS 10, Pearson's correlation coefficient was performed. The $\mathrm{P} \leq 0.05$ were considered significant and sample size assumed $\mathrm{N}=5$.

\section{RESULTS}

We collected the required data by questionnaires and apparatus. Age, height, and weight from descriptive questionnaires; FES and ABC scores from fear of falling questionnaires; femur's neck, total neck, and L1-L4 BMD from DXA results; location of each body's link from Kinect; and finally, COP location was assessed from Wii balance board. We calculated body's COM and COM acceleration in ML and AP direction using MATLAB 2014. We then calculated the mean and standard deviation which are listed in the following tables.

\section{A. Raw data}

The mean and standard deviation of the age, height, weight, BMI, and FES of participants are shown in Table I:

TABLE I. MEAND AND STANDARD DEVIATION OF AGE, HEIGHT, WEIGHT, BMI, FES AND ABC SCORE OF PARTICIPANTS

\begin{tabular}{|c|c|c|}
\hline \multirow{2}{*}{ Parameters } & \multicolumn{2}{|c|}{ Summary of results } \\
\cline { 2 - 3 } & Mean & SD \\
\hline Age $($ years $)$ & 62.5 & 7.6 \\
\hline Height $(\mathrm{cm})$ & 154 & 6 \\
\hline Weight $(\mathrm{kg})$ & 67.8 & 11.5 \\
\hline BMI $\left.^{\mathrm{kg}} / \mathrm{m}^{2}\right)$ & 28.6 & 4.7 \\
\hline $\begin{array}{c}\text { FES score } \\
(0.25-1)\end{array}$ & 0.48 & 0.14 \\
\hline $\begin{array}{c}\text { ABC score } \\
(0-100)\end{array}$ & 64.7 & 21.5 \\
\hline
\end{tabular}

The mean and standard deviation of the femur's neck, total femur, and L1-L4 BMD are shown in Table II. TABLE II. MEAN AND STANDARD DEVIATION OF FEMUR'S
NECK, TOTAL FEMUR AND L1-L4 BMD
Osteoporosis Research Center, Tehran University of Medical Sciences 


\begin{tabular}{|c|c|c|}
\hline \multirow{2}{*}{ Parameters } & \multicolumn{2}{|c|}{ Summary of results } \\
\cline { 2 - 3 } & Mean & SD \\
\hline $\begin{array}{c}\text { Femur Neck } \\
\mathrm{BMD}\left(\mathrm{g} / \mathrm{cm}^{2}\right)\end{array}$ & 0.867 & 0.12 \\
\hline $\begin{array}{c}\text { Femur } \\
\mathrm{BMD}\left(\mathrm{g} / \mathrm{cm}^{2}\right)\end{array}$ & 0.896 & 0.16 \\
\hline $\begin{array}{c}\mathrm{L} 1-\mathrm{L} 4 \\
\mathrm{BMD}\left(\mathrm{g} / \mathrm{cm}^{2}\right)\end{array}$ & 1.096 & 0.16 \\
\hline
\end{tabular}

The mean and standard deviation of the ML and AP COM acceleration and COP-COM of participants are shown in Table III:

TABLE III. MEAN AND STANDARD DEVIATION OF ML AND AP COM ACCELERATION AND ML AND AP COP-COM

\begin{tabular}{|c|c|c|}
\hline \multirow{2}{*}{ Parameters } & \multicolumn{2}{|c|}{ Summary of results } \\
\cline { 2 - 3 } & Mean & SD \\
\hline $\begin{array}{c}\text { ML COM acceleration } \\
\left(\mathrm{cm} / \mathrm{s}^{2}\right)\end{array}$ & -0.37 & 0.10 \\
\hline $\begin{array}{c}\text { AP COM acceleration } \\
\left(\mathrm{cm} / \mathrm{s}^{2}\right)\end{array}$ & -0.197 & 0.55 \\
\hline $\begin{array}{c}\text { ML COP-COM } \\
(\mathrm{cm})\end{array}$ & 4.92 & 2.04 \\
\hline $\begin{array}{c}\text { AP COP-COM } \\
(\mathrm{cm})\end{array}$ & 3.44 & 1.03 \\
\hline
\end{tabular}

\section{B. Analysis}

Using NCSS 10 the correlation coefficient between dependent and independent variables was calculated and the result is shown in the following table:

TABLE IV. PEARSON CORREALTION COEFFICIENT TEST BETWEEN BALANCE PARAMETERS AND BMD RESULTS AND FEAR OF FALLING SCORES

\begin{tabular}{|c|c|c|c|c|}
\hline \multirow[b]{2}{*}{$\begin{array}{c}\text { Ind. } \\
\text { variable }\end{array}$} & \multicolumn{4}{|c|}{ Dependent variables } \\
\hline & $\begin{array}{c}M L \\
\text { cop-com }\end{array}$ & $\begin{array}{c}A P \\
\text { cop-com }\end{array}$ & ML Acc. & AP Acc. \\
\hline FES & $\begin{array}{c}-0.114 \\
(\mathrm{P}=0.043)\end{array}$ & $\begin{array}{c}0.596 \\
(\mathrm{P}=0.032)\end{array}$ & $\begin{array}{c}-0.529 \\
(\mathrm{P}=479)\end{array}$ & $\begin{array}{c}-0.508 \\
(\mathrm{P}=0.502)\end{array}$ \\
\hline $\mathrm{ABC}$ & $\begin{array}{c}0.095 \\
(\mathrm{P}=0.038)\end{array}$ & $\begin{array}{c}-0.631 \\
(\mathrm{P}=0.176)\end{array}$ & $\begin{array}{c}0.467 \\
(\mathrm{P}=0.348)\end{array}$ & $\begin{array}{c}0.447 \\
(\mathrm{P}=0.371)\end{array}$ \\
\hline $\begin{array}{l}\text { Femur } \\
\text { Neck }\end{array}$ & $\begin{array}{c}-0.656 \\
(\mathrm{P}=0.038)\end{array}$ & $\begin{array}{c}-0.471 \\
(\mathrm{P}=0.831)\end{array}$ & $\begin{array}{c}-0.960 \\
(\mathrm{P}=0.012)\end{array}$ & $\begin{array}{c}-0.968 \\
(\mathrm{P}=0.008)\end{array}$ \\
\hline Femur & $\begin{array}{c}-0.538 \\
(\mathrm{P}=0.050)\end{array}$ & $\begin{array}{c}-0.459 \\
(\mathrm{P}=0.709)\end{array}$ & $\begin{array}{c}-0.975 \\
(\mathrm{P}=0.006)\end{array}$ & $\begin{array}{c}-0.980 \\
(\mathrm{P}=0.004)\end{array}$ \\
\hline L1-L4 & $\begin{array}{c}-0.620 \\
(\mathrm{P}=0.039)\end{array}$ & $\begin{array}{c}-0.603 \\
(\mathrm{P}=0.937)\end{array}$ & $\begin{array}{c}-0.029 \\
(\mathrm{P}=0.961)\end{array}$ & $\begin{array}{c}-0.063 \\
(\mathrm{P}=0.993)\end{array}$ \\
\hline
\end{tabular}

The relationship between ML center of mass acceleration and femur's BMD is shown in Figure 1.

\section{ML com acceleration vs. Femur BMD}

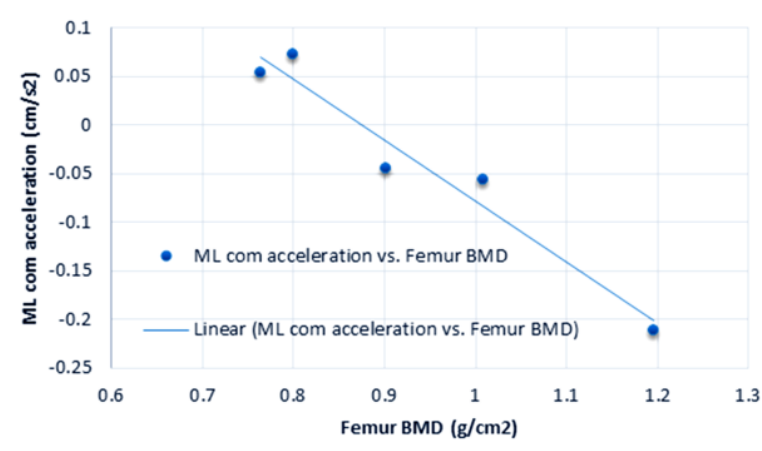

Figure 1. Mediolateral COM acceleration vs. femur's BMD

The relationship between AP center of mass acceleration and femur's BMD is shown in Figure 2.

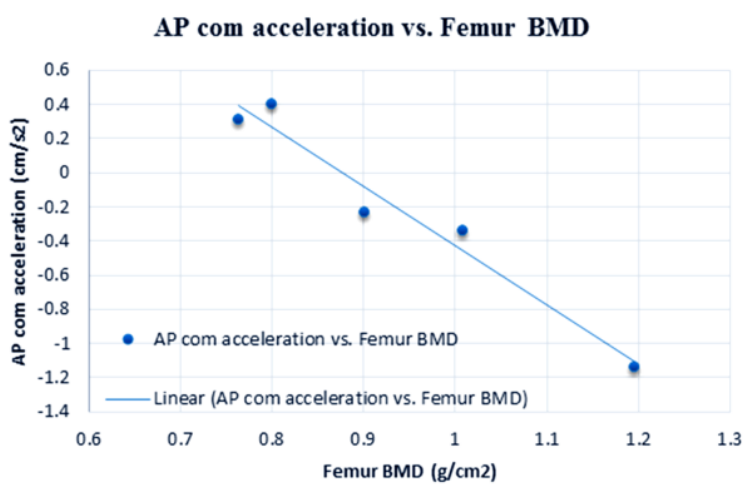

Figure 2. Anteroposterior COM acceleration vs. femur's BMD

\section{DISCUSSION}

In relation to bone mineral density and postural stability, Kuczyński M, et al. (2006) ${ }^{[23]}$ investigated the relationship between postural sway and unsteadiness by using viscoelastic model in osteoporotic patients. They studied COP in quiet stance in 37 postmenopausal women (aged 42-79 years), diagnosed with osteopenia or osteoporosis who engaged in a range of activity levels. Then, by using COP-COM, they computed the selected properties of postural mechanics (stiffness and viscosity) and dynamics (frequency and damping) of stance.

D. C. Abreu, et al. (2010) ${ }^{[24]}$ evaluated the relationship between balance and BMD loss by using Polhemic system. They separated people into three groups: 1) women with normal bone mineral density, 2) women with osteopenia, and 3) women with osteoporosis. They observed that the third group has the worst balance, possibly due to their body changes. Also, Brech GC, et al. (2013) [25] evaluated the association between osteoporosis and postural balance in 126 postmenopausal women aged 55-65 years. They separated people into two groups according to the bone mineral density values of their lumbar spine: the osteoporosis group and the control group. They also evaluated functional mobility, postural balance, muscle strength, and mean velocity of the COP. They observed 
postmenopausal women aged between 55 and 65 years do not present changes in postural balance irrespective of lumbar osteoporosis. Besides, greater COP mediolateral displacement is related to the occurrence of falls in postmenopausal women in the previous year.

Cangussu L. M. et al. (2012) ${ }^{[26]}$ evaluated the association between postural balance and BMD in postmenopausal women and its relation to risk for falls. They studied 225 women with age $\geq 45$ years and according to BMD divided them into two groups: T-score values $>-2.0 \mathrm{SD}(\mathrm{n}=140)$ and $\leq-2 \mathrm{SD}(\mathrm{n}=$ 85 ). They showed there is no differences between the groups ( $\mathrm{p}$ $<0.05)$ for stabilometric parameters.

Hita-Contreras F. et al. (2014) [27] evaluated the relationship between BMD and postural stability and the fear of falling in postmenopausal people. They studied118 postmenopausal women with age 50-65 years and according to their BMD values, participants were divided into two groups: $\mathrm{BMD}>-2.0 \mathrm{SD}(n=95)$ and $\leq-2.0 \mathrm{SD}(n=23)$. For postural stability tests, they used a resistive multi-sensor platform (Sensor Medica, Rome, Italy). They observed Spanish postmenopausal women under 65 years, a BMD $\leq-2.0 \mathrm{SD}$ is significantly associated with postural instability and an increased fear of falling, which are two highly influential factors in the risk of falling.

Based on the statistical analysis, there is a reverse correlation between femurs neck BMD and ML COP-COM displacement $(1-\beta=0.663, P=0.038, r=-0.656)$, ML acc. of COM $(1-\beta=0.942, P=0.012, r=-0.960)$, and AP acc. of COM (1- $\beta=0.977, P=0.008, r=-0.968)$. There is no correlation between ML COP-COM displacement and FES score $(1-\beta=$ $0.627, \mathrm{P}=0.043, \mathrm{r}=-0.114)$ and there is a direct relationship between AP COP-COM $(1-\beta=0.716, \mathrm{P}=0.032, \mathrm{r}=0.596)$. Also there is no correlation between ABC score and ML COPCOM displacement $(1-\beta=0.662, \mathrm{P}=0.038, \mathrm{r}=0.095)$. Moreover, we observed a reverse correlation between femur BMD and ML Acc. of COM $(1-\beta=0.992, \mathrm{P}=0.006, \mathrm{r}=-$ 0.975), and AP acc. of COM $(1-\beta=0.998, P=0.004, r=-$ 0.980). Besides, there is a reverse correlation between L1-L4 and ML COP-COM displacement $(1-\beta=0.654, \mathrm{P}=0.039, \mathrm{r}=$ $-0.620)$.

Given the desired statistical power of $\% 80$ or above, leads us to conclude that femurs neck and total femur BMD has a reverse correlation with ML and AP acceleration of COM. Besides, we observed a reverse correlation between L1-L4 BMD and ML COP-COM displacement. All in all, we recommend that increasing the sample size would lead us to more reliable conclusions between other parameters.

\section{CONCLUSION}

One of the advantages of our study is using the Wii balance board and Kinect as balance assessment tools; since, these apparatus are portable and cheaper than the regular balance assessment tools in laboratories.
For future directions, we believe that discovering the exact relation between bone density and balance error (COP-COM) enables us to predict the balance status of a patient by measuring the bone density instead of the more complicated and timeconsuming balance tests. Further research in this field would also facilitate the design of the equipment that prevent the rate of falling in patients. For example, by designing shoes that incorporate the balance error of a patient, we can reduce the fall risk of the patient and hence, the chance of bone fraction.

\section{REFERENCES}

[1] Reginster JY1, Burlet N (2006) Osteoporosis: a still increasing prevalence. Bone. 38(2 Suppl 1):S4-9.

[2] Siris E and Delmas PD (2008) Assessment of 10-year absolute fracture risk: a new paradigm with worldwide application. Osteoporos Int 19:383.

[3] Kanis JA, Johnell O, Oden A, et al. (2008) FRAXtrade mark and the assessment of fracture probability in men and women from the UK. Osteoporos Int 19:385.

[4] Fujiwara S, Nakamura T, Orimo H, et al. (2008) Development and application of a Japanese model of the WHO fracture risk assessment tool (FRAXtrade mark). Osteoporos Int 19:429.

[5] Tosteson AN, Melton LJ, 3rd, Dawson-Hughes B, et al. (2008) Costeffective osteoporosis treatment thresholds: the United States perspective. Osteoporos Int 19:437.

[6] Dawson-Hughes B, Tosteson AN, Melton LJ, 3rd, et al. (2008) Implications of absolute fracture risk assessment for osteoporosis practice guidelines in the USA. Osteoporos Int 19:449.

[7] Leslie WD (2008) Absolute fracture risk reporting in clinical practice: A physician-centered survey. Osteoporos Int 19:459.

[8] Sinaki, M., Brey, R. H., Hughes, C. A., Larson, D. R., and Kaufman, K. R. (2005). Balance disorder and increased risk of falls in osteoporosis and kyphosis: significance of kyphotic posture and muscle strength. Osteoporos. Int. 16, 1004-1010. doi:10.1007/s00198-004-1791-2

[9] Standring, S. (2004). Gray's Anatomy: The Anatomical Basis of Clinical Practice, 39th Edn. London: Elsevier.

[10] Bone, H. G., Greenspan, S. L., McKeever, C., Bell, N., Davidson, M., Downs, R. W., et al. (2000). Alendronate effects in postmenopausal women with low bone mineral density: Alendronate/Estrogen Study Group. J. Clin. Endocrinol. Metab. 85, 720-726. doi:10.1210/jc.85.2.720

[11] Osteoporosis: Two- volume set. (2013). edited by Robert Marcus, David Feldman, David W. Dempster, Marjorie Luckey, Jane A. Cauley. Fourth edition. Osteoporosis: Two- volume set. ISBN: 978-0-12-415853-5. page 863. MA, USA.

[12] Y. Ishikawa, N. Miyakoshi, Y. Kasukawa, M. Hongo, Y. Shimada. (2009). Spinal curvature and postural balance in patients with osteoporosis. Osteoporosis International. Volume 20, Issue 12, pp 20492053

[13] Anne Shumway-Cook, PT, Fapta, Marjorie H Woollacott. (2011). Motor Control: Translating Research Into Clinical Practice. Publisher: LIPPINCOTT WILLIAMS \& WILKINS. ISBN: 1451117108.Maryland, USA.

[14] Whiting, W. C., and Rugg, S. (2005). Dynatomy: Dynamic Human Anatomy, 1st Edn. Champaign: Human Kinetics.

[15] Ludlow, J. (2006). Osteoporosis - Weighing in on Aging Bones: Excessive Weight Loss and Age-Related Structural Change May Contribute to Fracture Risk. Medical News Today. Available at: http://www.medicalnewstoday.com/releases/44626.php

[16] Radaei F and Gharibzadeh S (2013) Relationship between bone mineral density and balance disorders in osteoporotic patients. Front. Bioeng. Biotechnol. 1:5. doi: 10.3389/fbioe.2013.00005

[17] H. S. Choi, Y. H. Kim. (2010). The Relationship between the COP-COM Variable and the Horizontal Acceleration of the Body in Postural Sway, Falling and Walking. DOI:10.1007/978-3-642-03882-2_74.

[18] D A Winter. (1995). Human balance and posture control during standing and walking. Gait\&Posture; Vol. 3: 193-214. 
[19] Hélène Corriveau, Réjean Hébert, François Prince, et al. (2001). Archives of Physical Medicine and Rehabilitation. Volume 82, Issue 1, Pages 8085

[20] Yardley, L., Beyer, N., Hauer, K., et al. (2005). Development and initial validation of the Falls Efficacy Scale-International (FES-I). Age and ageing, 34(6), 614-619.

[21] Baharlouei, Hamzeh, et al. "Cross-cultural validation of the Falls Efficacy Scale International (FES-I) using self-report and interview-based questionnaires among Persian-speaking elderly adults." Archives of gerontology and geriatrics 57.3 (2013): 339-344.

[22] Powell, LE \& Myers AM. The Activities-specific Balance Confidence (ABC) Scale. J Gerontol Med Sci 1995; 50(1): M28-34

[23] Kuczyński M1, Ostrowska B. (2006). Understanding falls in osteoporosis: the viscoelastic modeling perspective. Gait Posture. 23(1):51-8.
[24] D. C. Abreu, D. C. Trevisan, G. C. Costa, et al. (2010). The association between osteoporosis and static balance in elderly women. Volume 21, Issue 9, pp 1487-1491

[25] Brech GC1, Plapler PG, de Souza Meirelles E, et al. (2013). Evaluation of the association between osteoporosis and postural balance in postmenopausal women. Gait Posture. 38(2):321-5. doi: 10.1016/j.gaitpost.2012.12.012. Epub 2013 Jan 20.

[26] Cangussu, L. M., Nahas-Neto, J., Nahas, E. A. P., Barral, A. B. R., Buttros, D. A., \& Uemura, G. (2012). Evaluation of postural balance in postmenopausal women and its relationship with bone mineral density-a cross sectional study.BMC musculoskeletal disorders, 13(1), 2.

[27] Hita-Contreras, F., Martínez-López, E., González-Matarín, P., Mendoza, N., Cruz-Díaz, D., Ruiz-Ariza, A., \& Martínez-Amat, A. (2014). Association of bone mineral density with postural stability and the fear of falling in Spanish postmenopausal women. Maturitas, 79(3), 322-328. 